STUDI

FRANCESI

\section{Studi Francesi}

Rivista quadrimestrale fondata da Franco Simone

190 (LXIV | I) | 2020

Varia - fasc. I - gennaio-aprile 2020

\title{
TOUSSAINT LOUVERTURE, Mémoires
}

\section{Elena Fermi}

\section{CpenEdition \\ Journals}

\section{Édition électronique}

URL : https://journals.openedition.org/studifrancesi/23344

DOI : $10.4000 /$ studifrancesi.23344

ISSN : 2421-5856

\section{Éditeur}

Rosenberg \& Sellier

\section{Édition imprimée}

Date de publication : 1 avril 2020

Pagination : 231

ISSN : 0039-2944

\section{Référence électronique}

Elena Fermi, « toussaint Louverture, Mémoires », Studi Francesi [En ligne], 190 (LXIV | I) | 2020, mis en ligne le 01 mai 2020, consulté le 03 août 2021. URL : http://journals.openedition.org/studifrancesi/ 23344 ; DOI : https://doi.org/10.4000/studifrancesi.23344

Ce document a été généré automatiquement le 3 août 2021.

\section{(c) (†)}

Studi Francesi è distribuita con Licenza Creative Commons Attribuzione - Non commerciale - Non opere derivate 4.0 Internazionale. 


\section{TOUSSAINT LOUVERTURE, Mémoires}

\section{Elena Fermi}

\section{RÉFÉRENCE}

TOUSSAINT LOUVERTURE, Mémoires, éd. D. Desormeaux, Paris, Classiques Garnier, 2019, 260

pp.

Daniel Desormeaux livre aux lecteurs une édition critique des Mémoires de Toussaint Louverture. Écrites par le premier gouverneur noir de celle que l'on appelait encore la colonie de Saint-Domingue au crépuscule de sa vie, en 1802, pendant qu'il est prisonnier au Fort de Joux dans le Doubs, ces souvenirs occupent un espace d'assez peu de pages mais représentent un témoignage fondamental des faits conduisant à l'indépendance de l'île qui devint, en 1804, la première république noire de l'histoire. Desormeaux rétablit dans son introduction au volume l'histoire de cet ouvrage, à la genèse très complexe et aux éditions multiples. Il fait un véritable travail de génétiste en reconstruisant le parcours des quatre versions manuscrites existantes, toutes complètes malgré quelques variantes. On découvre ainsi qu'à la version originale, écrite de la main de Toussaint lui-même dans une langue mélangeant le français des colonisateurs au créole, s'en ajoutent trois autres, toutes rédigées en français sous la dictée ou la surveillance de leur auteur qui y intervient avec des ratures et des annotations dans les marges, ainsi qu'avec une note à la fin qui en atteste la véridicité. En mettant complètement de côté l'aspect autobiographique - on n'y trouve aucune information concernant la vie de l'ancien esclave -, Louverture tient à y justifier ses actions vis-à-vis du gouvernement français, en vue d'un possible procès qui n'aura jamais lieu. C'est le général de l'armée, le militaire de la République, qui se présente ainsi à ses contemporains et à la postérité en devenant le premier mémorialiste noir de l'Histoire, dans un pays - la France - où ce genre littéraire est particulièrement prisé, comme le dit Pierre Larousse dans son Grand dictionnaire universel $d u X I X^{\mathrm{e}}$ siècle. Desormeaux suit la genèse de l'ouvrage dès sa première édition, très tardive car elle ne paraît qu'en 1853, sous le Second Empire et en pleine atmosphère romantique. Il mène une enquête historique très précise, afin de mettre en relief les raisons de ce retard et 
offre une analyse très détaillée de la première édition de Saint-Rémy, en l'insérant dans le contexte de l'époque. Le problème de l'authenticité des Mémoires, soulevé par les critiques au fil des années et lié au fait que Louverture n'était pas à même d'écrire correctement en français mais se servait de secrétaires auxquels il dictait ses lettres et documents, interroge également le chercheur. Il cite, en guise de réponse, l'argumentation de Claude Lévi-Strauss à propos de l'écriture au service du pouvoir dans Tristes Tropiques - et celle de Pierre Bourdieu qui affirme dans Ce que parler veut dire que, pour raconter, il faut en avoir le pouvoir. Tout en laissant la question ouverte, Desormeaux défend l'hypothèse selon laquelle la dictée deviendrait chez Toussaint Louverture une forme d'écriture par procuration qui restituerait à l'homme d'action qu'il a été son plein pouvoir sur les mots. Le texte des Mémoires - écrit de jet par leur auteur - est d'abord présenté dans sa version française. Desormeaux commente dans les notes finales son travail de réédition; il informe les lecteurs de ses interventions concernant la modernisation de l'orthographe et la reconstitution des règles linguistiques les plus élémentaires, qu'il a décidé de faire afin de faciliter l'accès à l'ouvrage. Il signale également les variantes présentes dans les différents manuscrits, afin de restituer le plus fidèlement possible l'originalité de l'œuvre. Les Annexes offrent la possibilité de comparer l'édition au manuscrit original, dont on retrouve la transcription sans aucune intervention corrective, ainsi que de consulter d'autres documents très significatifs pour reconstruire l'histoire des derniers mois de vie de Louverture. On y trouve le Journal du Général Caffarelli, qui résume l'interrogatoire mené par celui-ci à l'arrivée de Toussaint au Fort de Joux, ainsi que deux billets et une lettre de ce dernier et la lettre que monsieur Jeannin - secrétaire au Fort de Joux auquel le prisonnier avait dicté ses mémoires - envoya à Isaac Louverture pour l'informer de la présence, au dépôt du château, d'une somme provenant de la vente des effets de son père. On peut y lire enfin le texte de la Constitution de Saint-Domingue, promulguée en 1801 par les députés réunis en assemblée centrale, que Toussaint tenta de faire valider par la métropole.

Cette réédition des Mémoires de Toussaint Louverture a le mérite de faire redécouvrir la portée historique et politique de ce document mais aussi la personnalité de leur auteur. 